\title{
Electrophoretic Deposition of Aluminum Nitride from Its Suspension in Acetylacetone Using Iodine as an Additive
}

\author{
Bizuneh Workie, ${ }^{1}$ Brian E. McCandless, ${ }^{2}$ and Zewdu Gebeyehu ${ }^{3}$ \\ ${ }^{1}$ Department of Chemistry, Delaware State University, 1200 N. DuPont Highway, Dover, DE 19901, USA \\ ${ }^{2}$ Institute of Energy Conversion, University of Delaware, Newark, DE 19716, USA \\ ${ }^{3}$ Department of Chemistry, Columbus State University, Columbus, GA 31907, USA
}

Correspondence should be addressed to Bizuneh Workie; bworkie@desu.edu

Received 20 June 2012; Revised 28 August 2012; Accepted 26 November 2012

Academic Editor: Mitchell R. M. Bruce

Copyright (C) 2013 Bizuneh Workie et al. This is an open access article distributed under the Creative Commons Attribution License, which permits unrestricted use, distribution, and reproduction in any medium, provided the original work is properly cited.

\begin{abstract}
We have studied electrophoretic deposition of AlN from its suspension in acetylacetone with $\mathrm{I}_{2}$ as an additive. AlN powder with particle size $<10 \mu \mathrm{m}$ is dispersed to produce a positive charge and deposited on the cathode by applying fields greater than $10 \mathrm{~V} / \mathrm{cm}$ between the electrodes. X-ray diffraction and FTIR studies indicate that the AlN before and after deposition has the same composition and structure. An increase in the amount of AlN in the suspension, the deposition potential, and the deposition time results in a linear increase in the weight of the AlN deposited. Electrophoretic deposition from $10 \mathrm{~g} / \mathrm{L}$ AlN suspension shows an initial increase in the weight of AlN deposited with the concentration of $\mathrm{I}_{2}$, and the weight of AlN decreases after reaching a maximum at $0.20 \mathrm{~g} / \mathrm{L} \mathrm{I}_{2}$.
\end{abstract}

\section{Introduction}

In this paper, we describe a simple method of coating aluminum nitride, AlN, using an electrophoretic deposition technique in nonaqueous medium. We performed the coating from a suspension of AlN in acetylacetone using $I_{2}$ as an additive on the $\mathrm{Al}$ cathode. We provide material characterization data such as X-ray diffraction (XRD), scanning electron microscopy (SEM), and Fourier transform infrared (FTIR) spectra of the coated film. We also discuss the effect of various parameters such as potential, deposition time, and the amount of $\mathrm{I}_{2}$ and AlN present in the suspension on the amount of AlN deposited.

AlN coating has a wide range of practical application. It is used as an electronic packaging material due to its high thermal conductivity, $320 \mathrm{~W} /(\mathrm{mK})$, and electrical resistivity, $>10^{13} \Omega \mathrm{cm}$ [1-3]. It has also applications in the optical industry for dielectric and protective coatings, thin film transducers, and surface acoustic wave (SAW) devices [4-7].

Various physical and chemical methods are used to prepare AlN films. These include chemical vapor deposition, reactive sputtering and evaporation, and ion beam nitridation [8-16]. Electrophoretic deposition is an alternative method of coating. In electrophoretic deposition, charged particles migrate independently of one another in a suspension under the influence of an electric field and are deposited onto an electrode. The appealing features of this coating method are that the coating can be performed within a short period, it does not require expensive apparatus, it is well suited for coating irregularly shaped objects, and it is suitable for mass production. The theoretical and its general advantages and applications for ceramic coatings have been well documented in a review by Sarker and Nicholson [17] and van der Biest and Vandeperre [18]. The theoretical and experimental development of the technique has also been reviewed by Heavens [19]. Various reports have appeared in the literature on the application of the technique for ceramic coatings [18-37].

Electrophoretic deposition from aqueous or nonaqueous suspensions containing water has problems due to the electrolysis of water that takes place together with the deposition. The production of $\mathrm{H}_{2}$ and/or $\mathrm{O}_{2}$ gases during the electrolysis 
prevents the formation of a well-adhered and uniform film. The electrolysis of water also lowers the current efficiency of the electrophoresis process. A longer period of coating is thus required for the deposition of powdered layer of significant thickness.

These problems of electrophoretic deposition in the presence of water are entirely eliminated using nonaqueous organic media such as benzene or ketones. The oxidationreduction potentials of these organic solvents are extremely high, thus preventing the formation of gases due to electrolysis. This improves the quality of the coated film and also results in high current efficiency. Electrophoretic coating from organic solvents, however, requires several hundred volts of potential since the charges adhered to the particles in the suspension are extremely low due to the small amount of free ions present in the pure solvents. This problem has been solved by using $\mathrm{I}_{2}$ as an additive in acetylacetone as the suspension media [20]. The reaction of acetylacetone and iodine produces free protons that will be adsorbed on the particles of the suspension increasing their surface charges.

Electrophoretic deposition of AlN ceramic coating has been reported by various workers from its suspension in ethanol using various additives [21-26]. In the work of Mortiz and Reetz [21], poly(acrylic acid)-coated AlN powder emulsified in ethanol was deposited on Pt resulting in an AlN coating. Vandeperre et al. [22] deposited AlN on a cathode from ethanol in the presence of acetic acid. Mortiz and Müller [23] electrophoretically deposited AlN from ethanol using polyacrylic acid and triethylamine as additives. Jian-Feng et al. [24] used polyacrylic acid as a dispersant for EPD of AlN from its suspension in ethanol. Abdoli et al. [25] used ethanol in the presence of iodine as its suspension medium for the coating of AlN. Zhang and coworkers [26] conducted electrophoretic deposition of AlN from its suspension in ethanol in the presence of triethylamine.

Wade and Crooks $[27,28]$ electrophoretically deposited AlN polymer precursor on $\mathrm{n}-\mathrm{Si}$ cathode from a suspension in $\mathrm{CH}_{3} \mathrm{CN}$ and calcined the deposited film at a temperature of $1100 \mathrm{C}$ in flowing $\mathrm{NH}_{3}$ to AlN ceramic coating. Our work $[29,30]$ has shown that electrophoretic deposition can be performed from the suspension of AlN in acetylacetone using iodine as an additive

\section{Experimental}

AlN powder ( $98 \%$ pure and particle size $<10 \mu \mathrm{m})$ from Aldrich was used with no further treatment. The suspension was prepared in a solution of $\mathrm{I}_{2}$ (EM Science, $99.8 \%$ pure) in acetylacetone (Aldrich). Unless otherwise noted, $10 \mathrm{~g} / \mathrm{L}$ AlN suspension in $0.2 \mathrm{~g} / \mathrm{L} \mathrm{I}_{2}$ /acetylacetone was used for all electrophoretic deposition works.

Electrophoretic deposition was carried out in a cylindrical cell of about $3.0 \mathrm{~cm}$ diameter and a capacity of $50 \mathrm{~mL}$. The cathode and the anode used were $1 \times 3 \mathrm{~cm} \mathrm{Al}$ (JohnsonMathey, $98.5 \%$ pure, and $1.00 \mathrm{~mm}$ thick), and they were approximately positioned $1 \mathrm{~cm}$ apart parallel to each other. $20 \mathrm{~mL}$ suspension was used for all works. The Al cathode was cleaned with soap water, dipped in $1 \mathrm{M} \mathrm{H}_{2} \mathrm{SO}_{4}$ acid (heated to a temperature of about $75 \mathrm{C}$ ), rinsed with deionized water and ethanol, and finally dried under a stream of $\mathrm{N}_{2}$. A potential of 10 to $50 \mathrm{~V}$ was applied with a DC power supply (Sorensen Model DCR 150-3B produced by Raytheon Co. or BK Precision Model 1602 High Voltage Power Supply). For all potentials used, a well-adhered electrophoretically deposited film was observed on the cathode covering the entire electrode. Our adherence test of the films involved withstanding of a light wiping with a lab wipe followed by washing with ethanol and $\mathrm{N}_{2}$ drying. The weight of the deposit was obtained by taking the weight difference of the Al cathode before and after electrophoretic deposition.

Prior to the electrophoretic deposition, the suspension was ultrasonically stirred for about $1 \mathrm{~h}$ to break up the AlN powder particles. In order to prevent settling of AlN powder, the suspension was stirred gently and continuously with a magnetic stirrer by the time the deposition was carried out. Conductivity and $\mathrm{pH}$ of the $\mathrm{I}_{2}$ /acetylacetone solution before and after adding AlN were measured at room temperature $5 \mathrm{~min}$ after the electrodes were immersed in the suspension.

To identify the structure of the coated film, powder X-ray diffraction (XRD) was conducted on both a scraped powder and the deposited film using a Philips/Norelco computercontrolled diffractometer using $\mathrm{Cu} K \alpha$ radiation at $35 \mathrm{kV}$ and $20 \mathrm{~mA}$ in Bragg-Brentano parafocusing geometry. The detector stepped from 10 to 90 degrees $2 \theta$ using a step size 0.05 degree/step and counting time of $4 \mathrm{~s} / \mathrm{step}$. To study the surface morphology of the deposited film, scanning electron microscopy (SEM) study was conducted using an Amray 1810 microscope with Oxford Instruments INCA framegrabbing software.

FTIR analysis of the original powder of AlN before deposition and a film scraped from the Al cathode was performed using Nicolet MAGNA-IR 550 Series II spectrometer. The IR spectrum of the original powder of AlN was compared with the spectrum of the scraped film to see if any chemical species were adsorbed or incorporated in the film by the time the coating was performed. The samples for the FTIR study were prepared as $\mathrm{KBr}$ pellets.

\section{Results and Discussion}

3.1. Electrophoretic Deposition Study. Table 1(a) shows that the conductivity of $\mathrm{I}_{2}$ /acetylacetone increases with an increase in $\mathrm{I}_{2}$. It has been reported that this increase in conductance with an increase in $\mathrm{I}_{2}$ concentration is due to the production of free protons from the reaction of acetylacetone and $\mathrm{I}_{2}$, equation (1) [20]. This is in agreement with the $\mathrm{pH}$ results shown in Table 1 (b). Consider

$$
\begin{aligned}
\mathrm{CH}_{3}-\mathrm{CO}-\mathrm{CH}_{2}-\mathrm{CO}-\mathrm{CH}_{3} & \\
& \stackrel{\mathrm{I}_{2}}{\leftrightarrows} \mathrm{ICH}_{2}-\mathrm{CO}-\mathrm{CH}_{2}-\mathrm{CO}-\mathrm{CH}_{2} \mathrm{I}+2 \mathrm{I}^{-}+2 \mathrm{H}^{+}
\end{aligned}
$$

We observed a decrease in conductivity and an increase in $\mathrm{pH}$ upon addition of AlN to $\mathrm{I}_{2}$ /acetylacetone, Tables 1 (a) and 1 (b). This suggests the reduction of the free protons by the AlN particles. We believe that this is due to the adsorption of protons on the surface of the AlN particles. This is in 
TABle 1: (a) Effect of AlN on the conductivity $(\kappa)$ of $\mathrm{I}_{2}$ /acetylacetone. (b) Effect of AlN on the $\mathrm{pH}$ of $\mathrm{I}_{2}$ /acetylacetone.

(a)

\begin{tabular}{lcc}
\hline $\begin{array}{l}\text { Amount of } \mathrm{I}_{2} \\
(\mathrm{~g} / \mathrm{L})\end{array}$ & $\begin{array}{c}\kappa(\mu \mathrm{S} / \mathrm{cm}) \text { of } \\
\mathrm{I}_{2} / \text { acetylacetone } \\
\text { with no AlN }\end{array}$ & $\begin{array}{c}\kappa(\mu \mathrm{S} / \mathrm{cm}) \text { of } \\
\mathrm{I}_{2} / \text { acetylacetone } \\
\text { with } 10 \mathrm{~g} / \mathrm{L} \text { AlN }\end{array}$ \\
\hline 0 & 0.7 & 0.8 \\
0.1 & 10.9 & 9.4 \\
0.2 & 21.8 & 19.7 \\
0.3 & 35.4 & 32.7 \\
0.4 & 47.8 & 44.6 \\
0.6 & 73.1 & 70.2 \\
0.8 & 99.4 & 96.9 \\
\hline
\end{tabular}

(b)

\begin{tabular}{lcc}
\hline $\begin{array}{l}\text { Amount of } \mathrm{I}_{2} \\
(\mathrm{~g} / \mathrm{L})\end{array}$ & $\begin{array}{c}\mathrm{pH} \text { of } \\
\mathrm{I}_{2} / \text { acetylacetone } \\
\text { with no AlN }\end{array}$ & $\begin{array}{c}\mathrm{pH} \text { of } \\
\mathrm{I}_{2} / \text { acetylacetone } \\
\text { with 10 g/L AlN }\end{array}$ \\
\hline 0 & 5.01 & 5.04 \\
0.1 & 4.59 & 4.65 \\
0.2 & 4.29 & 4.56 \\
0.3 & 3.92 & 4.29 \\
0.4 & 0.91 & 1.89 \\
0.6 & 0.05 & 0.76 \\
\hline
\end{tabular}

agreement with the electrophoretic deposition result, where the positively charged AlN particles undergo electrophoretic migration in an electric field and selectively coated on the cathode.

The weight of the coated film in the electrophoretic deposition is a function of various factors. These are the amount of the particles in the suspension $(C)$, the permittivity of vacuum $\left(\varepsilon_{0}\right)$, the relative permittivity of the dispersing medium $\left(\varepsilon_{r}\right)$, the zeta potential of the particles $(\zeta)$, the viscosity of the solvent $(\eta)$, the applied potential $(E)$, the distance between the electrodes $(L)$, and the deposition time $(t)$. In the initial period of the deposition, ignoring the charge carried by the free ions, the weight of the charged particles deposited per unit area $(w)$ is expressed using $(2)[20,31]$ as follows:

$$
w=2 / 3\left[C \varepsilon_{o} \varepsilon_{r} \zeta \eta^{-1} E L^{-1} t\right]
$$

From (2), it can be seen that the deposition yield increases with any of the parameters except the viscosity of the solvent and the distance between the electrodes.

To investigate the effect of $\mathrm{I}_{2}$ concentration on the amount of AlN deposited, we conducted electrophoretic deposition studies at $20 \mathrm{~V}$ for $5 \mathrm{~min}$ on $10 \mathrm{~g} / \mathrm{L}$ of AlN suspension in various concentrations of $\mathrm{I}_{2}$ /acetylacetone, and the result is shown in Figure 1. Figure 1 illustrates an initial increase in the weight of AlN deposited with the concentration of $\mathrm{I}_{2}$ and a decrease after reaching a maximum at $0.20 \mathrm{~g} / \mathrm{L} \mathrm{I}_{2}$. Ishiria and coworkers observed and explained similar phenomenon for electrophoretic deposition of $\mathrm{Y}_{2} \mathrm{O}_{3}$-stablized $\mathrm{ZrO}_{2}$ film [20].

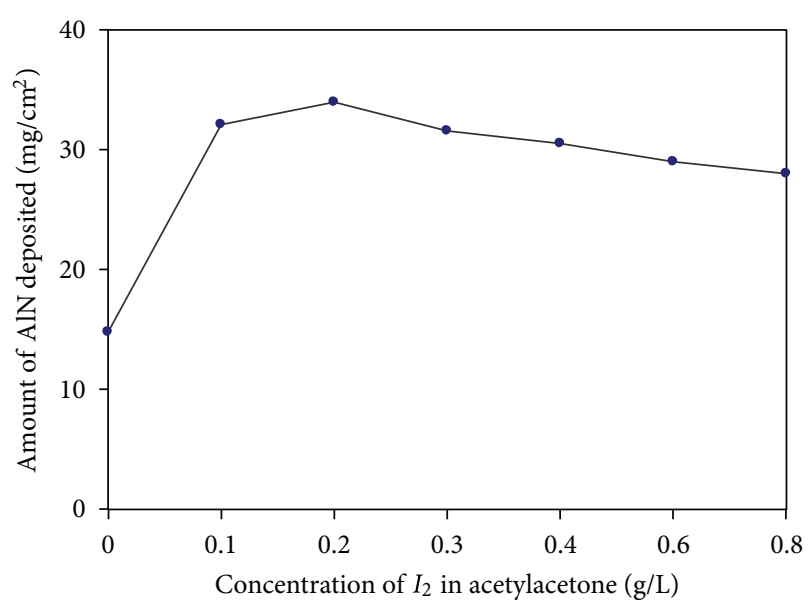

Figure 1: The effect of $I_{2}$ concentration on the weight of AlN deposited for the electrophoretic deposition of AlN in $\mathrm{I}_{2}$ /acetylacetone. Deposition potential and time are $20 \mathrm{~V}$ and $5 \mathrm{~min}$, respectively. The amount of AlN in the suspension is $10 \mathrm{~g} / \mathrm{L}$.

An initial increase in the amount of AlN deposited is due to the adsorbed proton that increases the surface charge of AlN with a subsequent increase in the zeta potential $(\zeta)$ and the amount of AlN deposited, equation (2). Further addition of $\mathrm{I}_{2}$ results in the formation of free protons in the suspension. Since the mobility of the protons is much higher than the AlN particles, most of the charges will be carried by the protons, thus decreasing the amount of AlN deposited. Figure 1 also demonstrates that the highest deposition rate of AlN took place in $0.2 \mathrm{~g} / \mathrm{L} \mathrm{I}_{2} /$ acetylacetone, in which the maximum weight of the coated AlN was obtained. We conducted all the subsequent studies using AlN deposited in this medium of $\mathrm{I}_{2}$ /acetylacetone.

To examine the effect of deposition time on the weight of AlN deposited, we conducted electrophoretic deposition at $20 \mathrm{~V}$ for a time range of 0 to $5 \mathrm{~min}$. Figure 2 shows that the weight of the coated AlN increases linearly with the deposition time according to (2). We observed a deviation from this linearity at longer duration of electrophoresis. This is due to the smaller value of the mobility of the positively charged AlN particles than the theoretical value used in the derivation of (2) [20]. As the deposition time becomes longer, the initially coated film and ions accumulated at the electrode surface shield the electric field applied to the suspension. This decreases the mobility of the AlN particles from the theoretical value.

Figures 3 and 4 show the effect of deposition potential and the amount of AlN in the suspension on the weight of the coated AlN film, respectively. In both cases, there is a linear increase of the deposited weight of AlN in agreement with (2).

3.2. Characterization of the Deposited Film. The surface morphology of the Al substrate and the AlN film on Al substrate is shown in the SEM micrographs of Figures 5(a) and 5(b). Figure 5(b) shows the SEM micrograph of AlN film deposited from $10 \mathrm{~g} / \mathrm{L}$ AlN suspension in $0.2 \mathrm{~g} / \mathrm{L} \mathrm{I}_{2}$ /acetylacetone at 


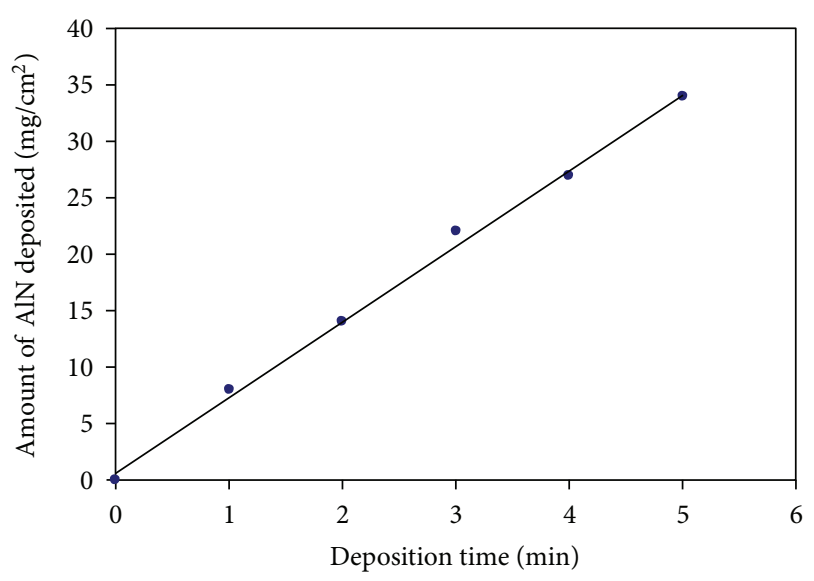

FIgURE 2: The effect of deposition time on the weight of AlN deposited for electrophoretic deposition of AlN in $0.2 \mathrm{~g} / \mathrm{L}$ $\mathrm{I}_{2}$ /acetylacetone. Deposition potential and the amount of AlN in the suspension are $20 \mathrm{~V}$ and $10 \mathrm{~g} / \mathrm{L}$, respectively.

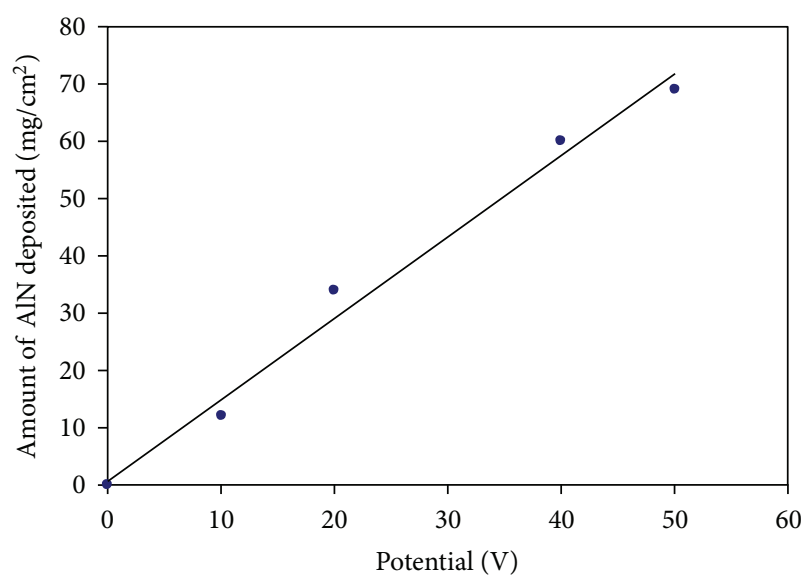

FIGURE 3: The effect of potential on the weight of AlN deposited for electrophoretic deposition of AlN in $0.2 \mathrm{~g} / \mathrm{L}$ in $\mathrm{I}_{2} /$ acetylacetone. Deposition time and the amount of $\mathrm{AlN}$ in the suspension are $5 \mathrm{~min}$ and $10 \mathrm{~g} / \mathrm{L}$, respectively.

a potential of $20 \mathrm{~V}$ for 5 minutes. The deposited material was continuous and well adhered.

The broad X-ray diffraction patterns of the Al foil, the AlN powder, the coated foil, and the coating scraped from the $\mathrm{Al}$ foil after deposition are shown in Figure 6(a).

Figure 6(b) shows the detail of the AlN coated Al foil sample. Table 2 lists the observed XRD reflections of AlN powder, coated $\mathrm{Al}$ foil, and the scraped coating, along with the d-spacings for $\mathrm{Al}$ and AlN standards. All of the observed peaks can be adequately indexed using the ICDD standard patterns for cubic Al (ICDD no. 4-787) and hexagonal AlN (ICDD no. 25-1133), indicating that the AlN starting powder and deposited AlN coatings are single phase. The $2 \theta$ measurement precision is $\pm 0.05 \mathrm{deg}$, which yields $\mathrm{d}$-spacing precision of $\pm 0.003 \AA$ at $2 \theta=40 \mathrm{deg}$ and $\pm 0.0003 \AA$ at $2 \theta=80 \mathrm{deg}$. The measured $\mathrm{d}$-spacings are in reasonable agreement with the standard values within this measurement precision. The AlN powder, the AlN coating, and the scraped AlN coating

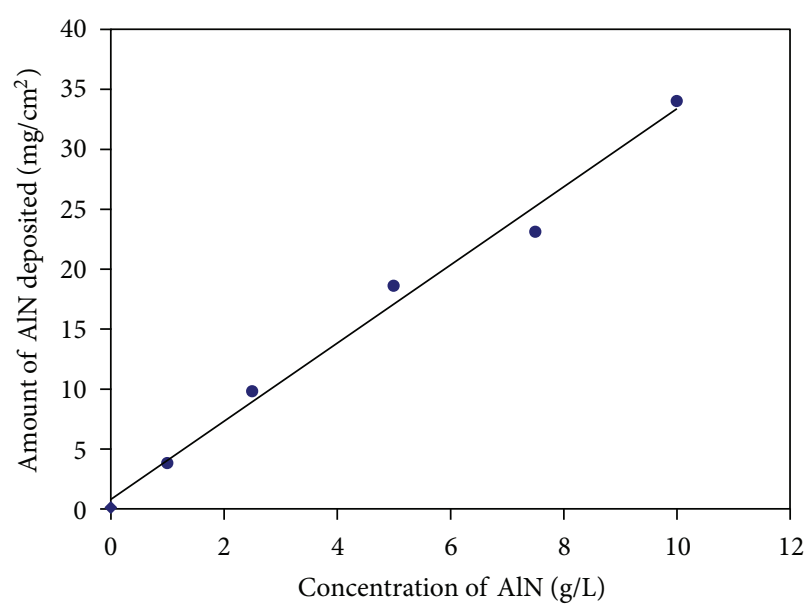

Figure 4: The effect of the amount of AlN in the suspension on the weight of AlN deposited for electrophoretic deposition of AlN in $0.2 \mathrm{~g} / \mathrm{L} \mathrm{I}_{2}$ /acetylacetone. Deposition potential and time are $20 \mathrm{~V}$ and $5 \mathrm{~min}$, respectively.

all exhibit random intensity patterns, corresponding closely to the published standard. The XRD peak profiles of $\mathrm{Al}$ and AlN peaks do not exhibit anomalous broadening, indicating that the diffracting domains have a narrow lattice parameter distribution, with domain size greater than $100 \mathrm{~nm}$.

FTIR transmission spectra of the original AlN powder before coating and the scraped powder of the deposited film from the cathode are shown in Figure 7. The broad peak at about $800 \mathrm{~cm}^{-1}$ in both cases is due to the $\mathrm{Al}$ N stretching vibration. From Figure 7, it is also possible to see that the scraped film powder has almost the same transmission spectrum as the original powder. This shows the absence of chemical species adsorbed or incorporated from the suspension into the film during electrophoretic deposition.

\section{Conclusion}

In this study, we have shown that electrophoretic deposition of AlN in nonaqueous medium, acetylacetone, leads to the formation of a deposited film on the Al cathode with $\mathrm{I}_{2}$ used as an additive. The weight of the AlN deposited shows a linear increase with the weight of AlN in the suspension, deposition time, and the potential applied in agreement with the theoretical prediction.

Nonaqueous electrophoretic deposition has an advantage of producing a better quality coating than aqueous suspensions. This is due to the absence of $\mathrm{H}_{2}$ and/or $\mathrm{O}_{2}$ gases that will be produced from the electrolysis of water. Its higher current efficiency also makes it suitable for quantitative production of powdered layer in a shorter period of time than aqueous suspension. Compared with other coating techniques of AlN such as chemical or vapor deposition, ion beam nitridation, or reactive sputtering, electrophoretic deposition has some general advantages. These include short period of coating, little restriction on the shape of the substrates, and use of simple deposition apparatus. 
TABLE 2: The observed reflections of AlN powder, coated $\mathrm{Al}$ foil, the scraped coating, and $d$-spacing for $\mathrm{Al}$ and $\mathrm{AlN}$ standards.

\begin{tabular}{lccccc}
\hline Al foil & $\begin{array}{c}\text { AlN } \\
\text { powder }\end{array}$ & $\begin{array}{c}\text { Coated } \\
\text { Al foil }\end{array}$ & $\begin{array}{c}\text { Scraped } \\
\text { coating }\end{array}$ & $\begin{array}{c}\text { ICDD } \\
4-787 \\
\text { Al }\end{array}$ & $\begin{array}{c}\text { ICDD } \\
25-1133 \\
\text { AlN }\end{array}$ \\
\hline & 2.696 & 2.704 & 2.700 & & 2.695 \\
& 2.493 & 2.499 & 2.496 & & 2.490 \\
& 2.372 & 2.378 & 2.375 & & 2.371 \\
2.342 & & 2.348 & & 2.338 & 1.829 \\
2.028 & & 2.030 & 1.831 & & 1.5559 \\
& 1.829 & 1.833 & 1.557 & & 1.4133 \\
1.433 & 1.556 & 1.559 & & & 1.3475 \\
& 1.413 & & & & 1.3194 \\
& 1.347 & & & & 1.314 \\
1.221 & 1.320 & 1.322 & & & \\
\hline
\end{tabular}
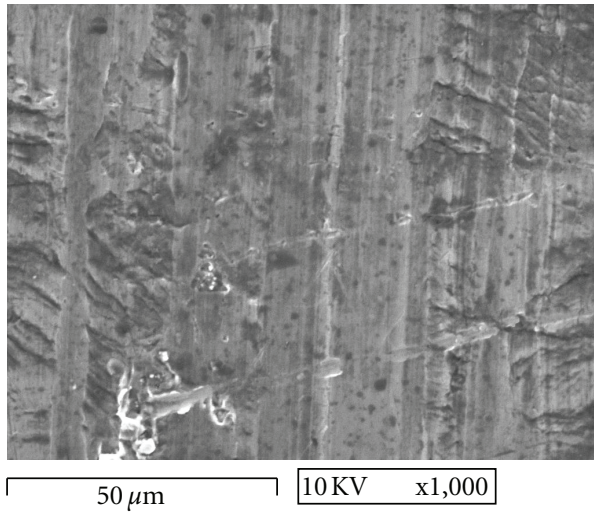

(a)

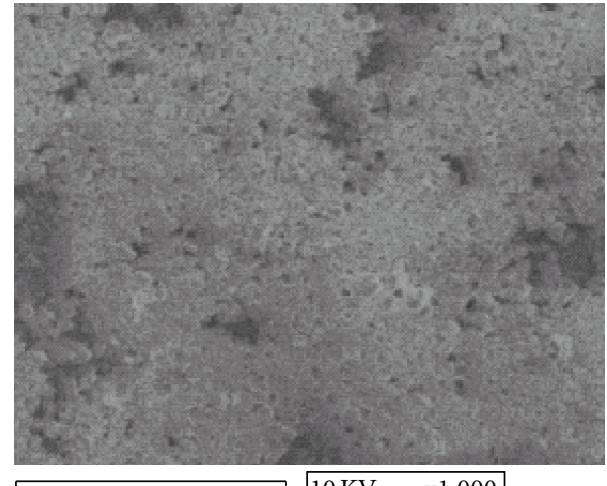

$50 \mu \mathrm{m}$

(b)

FIGURE 5: (a) SEM micrograph of bare Al substrate. (b) SEM micrograph of an AlN coating on Al cathode for electrophoretic deposition of AlN in $0.2 \mathrm{~g} / \mathrm{L} \mathrm{I}_{2} /$ acetylacetone at a potential of $20 \mathrm{~V}$. Deposition time and the amount of AlN in the suspension are $5 \mathrm{~min}$ and $10 \mathrm{~g} / \mathrm{L}$, respectively.

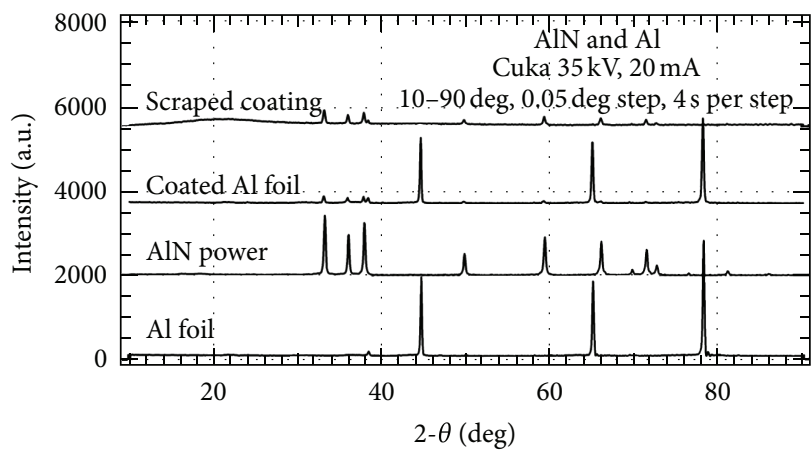

(a)

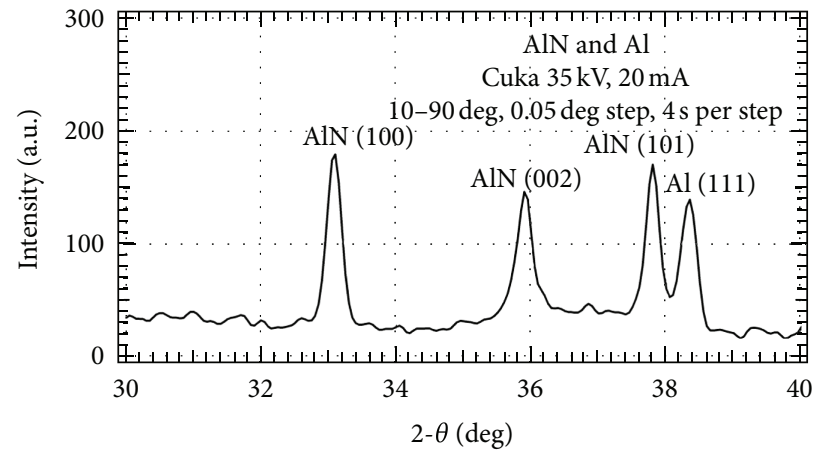

(b)

FIGURE 6: XRD diffraction patterns of (a) an Al cathode foil, AlN powder before coating, an Al cathode with AlN, and AlN film scraped from the $\mathrm{Al}$ cathode. (b) Detail of the AlN-coated Al cathode sample. 


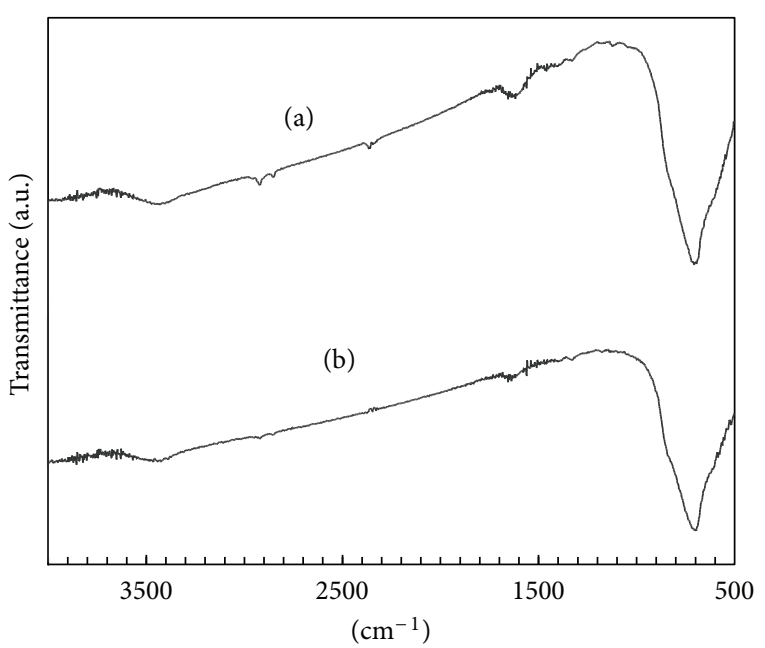

FIgure 7: Transmission FTIR spectra: (a) The original AlN powder before electrophoretic deposition; (b) The AlN film scraped from the $\mathrm{Al}$ cathode.

\section{Conflict of Interests}

All the authors of the paper declare that they do not have a direct financial relation with any commercial identity mentioned in the paper that might lead to a conflict of interests for any of the authors.

\section{Acknowledgments}

The authors gratefully acknowledge the National Science Foundation's Historically Black College and UniversitiesUndergraduate Program (HBCU-UP) of Delaware State University for the support of this research.

\section{References}

[1] L. M. Sheppard, "Aluminum nitride: a versatile but challenging material," The Bulletin of the American Ceramic Society, vol. 69, no. 11, pp. 1801-1812, 1990.

[2] N. Kuramoto and H. Taniguchi, "Transparent AIN ceramics," Journal of Materials Science Letters, vol. 3, no. 6, pp. 471-474, 1984.

[3] D. D. Marchant and T. E. Nemecek, "Aluminum nitride: preparation, processing, and properties," Advances in Ceramics, vol. 26, pp. 19-54, 1989.

[4] Y. Huokawa, K. Tsumi, K. Takamizawa, T. Kamata, and S. Noguchi, "A1N substrates with high thermal conductivity," IEEE Transactions on Components, Packaging, and Manufacturing Technology, vol. 8, pp. 247-252, 1985.

[5] N. Iwase, K. Anzai, and K. Shinozaki, "Aluminum nitride substrates having high thermal conductivity," Solid State Technology, vol. 29, no. 10, pp. 135-138, 1986.

[6] C. Sibran, R. Blanchet, M. Garrigues, and P. Viktorovitch, "Ion beam techniques combining insulator deposition and hydrogen plasma etching for III-V compound metal/insulator/semiconductor device applications," Thin Solid Films, vol. 103, no. 1-3, pp. 211-219, 1983.
[7] L. G. Pearce, R. L. Gunshor, and R. F. Pierret, "Aluminum nitride on silicon surface acoustic wave devices," Applied Physics Letters, vol. 39, no. 11, pp. 878-879, 1981.

[8] J. K. Liu, K. M. Lakin, and K. L. Wang, "Growth morphology and surface-acoustic-wave measurements of AIN films on sapphire," Journal of Applied Physics, vol. 46, no. 9, pp. 3703-3706, 1975.

[9] G. A. Slack and T. F. McNelly, "Growth of high purity AlN crystals," Journal of Crystal Growth, vol. 34, no. 2, pp. 263-279, 1976.

[10] P. N. Favennec, L. Henry, T. Janicki, and M. Salvi, "Protection du GaAs, Ga1-xAlxAs et GaAs1-xPx par du nitrure d'aluminium déposé par pulvérisation réactive," Thin Solid Films, vol. 47, no. 3, pp. 327-333, 1977.

[11] C. R. Aita, "Basal orientation aluminum nitride grown at low temperature by rf diode sputtering," Journal of Applied Physics, vol. 53, no. 3, p. 1807, 1982.

[12] L. Xinjiao, X. Zechuan, H. Ziyou et al., "On the properties of AlN thin films grown by low temperature reactive r.f. sputtering," Thin Solid Films, vol. 139, no. 3, pp. 261-274, 1986.

[13] H. Yamashita, K. Fukai, S. Misawa, and S. Yashida, "Optical properties of AlN epitaxial thin films in the vacuum ultraviolet region," Journal of Applied Physics, vol. 53, no. 2, p. 896, 1979.

[14] A. Singh, R. A. Lessard, and E. J. Knystautas, "IR and X-ray studies of ion-beam-synthesized aluminium nitride films," Thin Solid Films, vol. 138, no. 1, pp. 79-86, 1986.

[15] J. A. Taylor and J. W. Rabalais, "Reaction of $\mathrm{N}_{2}^{+}$beams with aluminum surfaces," The Journal of Chemical Physics, vol. 75, no. 4, pp. 1735-1745, 1981.

[16] J. M. Harper, J. J. Cuomo, and T. G. Hentzell, "Quantitative ion beam process for the deposition of compound thin films," Applied Physics Letters, vol. 41, no. 6, p. 547, 1983.

[17] P. Sarker and S. J. Nicholson, "Electrophoretic Deposition (EPD): mechanisms, kinetics, and application to ceramics," Journal of the American Ceramic Society, vol. 79, no. 8, pp. 1987-2002, 1996.

[18] O. O. van der Biest and L. J. Vandeperre, "Electrophoretic deposition of materials," Annual Review of Materials Science, vol. 29, pp. 327-352, 1999.

[19] S. N. Heavens, "Electrophoretic deposition as a processing route for ceramics," in Advanced Ceramic Process Technology, J. G. P. Binner, Ed., vol. 1, chapter 7, Noyes, Park Ridge, NJ, USA, 1990.

[20] T. Ishihara, K. Sato, and Y. Takita, "Electrophoretic deposition of $\mathrm{Y}_{2} \mathrm{O}_{3}$-stabilized $\mathrm{ZrO}_{2}$ electrolyte films in solid oxide fuel cells," Journal of the American Ceramic Society, vol. 79, no. 4, pp. 913-919, 1996.

[21] K. Mortiz and T. Reetz, "Electrophoretic shaping of aluminium nitride," CFI Ceramic Forum International, vol. 70, no. 7, pp. 348-350, 1993.

[22] L. Vandeperre, C. Zhao, and O. van der Biest, "Correlation between surface charge of a powder in water and electrophoretic deposition from non-aqueous media," British Ceramic Proceedings, vol. 61, pp. 69-74, 2000.

[23] K. Mortiz and E. Müller, "Investigation of the electrophoretic deposition behaviour of non-aqueous ceramic supensions," Journal of Materials Science, vol. 41, pp. 8047-8058, 2006.

[24] X. Jian-Feng, L. Jun, Z. Guo-Hong, Z. Hai-Long, and W. Shi-Wei, "Fabrication of aluminium nitride by electrophoretic deposition," Journal of Inorganic Materials, vol. 24, pp. 1151-1154, 2009.

[25] H. Abdoli, M. Zarabian, P. Alizadeh, and S. K. Sadrnezhaad, "Fabrication of aluminum nitride coatings by electrophoretic 
deposition: effect of particle size on deposition and drying behavior," Ceramics International, vol. 37, no. 1, pp. 313-319, 2011.

[26] H. Zhang, J. Li, G. Zhou, and S. Wang, "Fabrication of aluminium nitride by electrophoretic deposition," Advanced Materials Research, vol. 412, pp. 183-186, 2012.

[27] T. Wade and R. M. Crooks, "Electrochemical synthesis of ceramic materials. 4. Electrophoretic deposition of metal nitride ceramic precursors ," Chemistry of Materials, vol. 8, pp. 832-835, 1996.

[28] T. Wade, Electrochemical synthesis of metal-nitride ceramic powders and metal-nitride ceramic coatings [Ph. D. Dissertation], The University of New Mexico, 1995.

[29] B. Workie, B. McCandless, and Z. Gebeyehu, "Effects of various factors on the amount of AlN coated in electrophoretic deposition of aluminum nitride from its suspension in acetylacetone," Meeting Abstracts of the Electrochemical Society, vol. MA200601, p. 451, 2006.

[30] B. Workie, B. McCandless, and Z. Gebeyehu, "Non-aqueous electrophoretic deposition of aluminum nitride from its suspension in acetylacetone," Meeting Abstracts of the Electrochemical Society, vol. MA2006-01, p. 450, 2006.

[31] H. C. Hamaker, "Formation of a deposit by electrophoresis," Transactions of the Faraday Society, vol. 36, pp. 279-287, 1940.

[32] G. E. F. Brewer, "Electrodeposition of ceramic coatings," American Ceramic Society Bulletin, vol. 51, pp. 216-217, 1972.

[33] J. Mizuguchi, K. Sumi, and T. Muchi, "Highly stable nonaqueous suspension for the electrophoretic deposition of powdered substances," Journal of the Electrochemical Society, vol. 130, no. 9, pp. 1819-1825, 1983.

[34] H. Nojima, H. Shintaku, M. Nagata, and M. Koba, "Fabrication of Y-Ba-Cu-O superconducting films on $\mathrm{Cu}$ substrates by an electrophoretic deposition technique," Japanese Journal of Applied Physics, vol. 29, p. L1655, 1990.

[35] H. Nojima, M. Nagata, H. Shintakiu, and M. Koba, "Fabrication of ag-doped $\mathrm{Y}_{1} \mathrm{Ba}_{2} \mathrm{Cu}_{3} \mathrm{O}_{7-x}$ superconducting films on $\mathrm{Cu}$ substrates by electrophoretic deposition," Japanese Journal of Applied Physics, vol. 30, p. L1166, 1991.

[36] Y. Hirata, A. Nishimoto, and Y. Ishihara, "Forming of alumina powder by electrophoretic deposition," Seramikusu Kyukai Ronbunshi, vol. 99, pp. 108-113, 1991.

[37] T. Wade, J. Park, E. G. Graza, C. B. Ross, D. M. Smith, and R. M. Crooks, "Electrochemical synthesis of ceramic materials. 2. Synthesis of aluminum nitride (AlN) and an AlN polymer precursor: chemistry and materials characterization," Journal of the American Chemical Society, vol. 114, no. 24, pp. 9457-9464, 1992. 

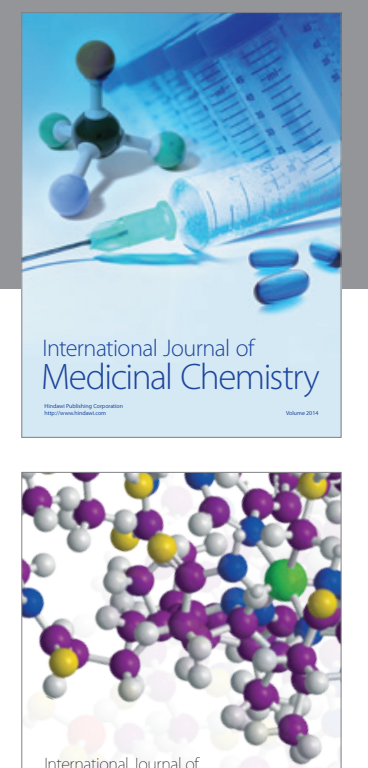

\section{Carbohydrate} Chemistry

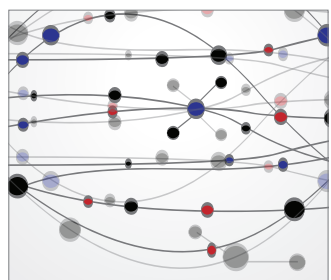

The Scientific World Journal
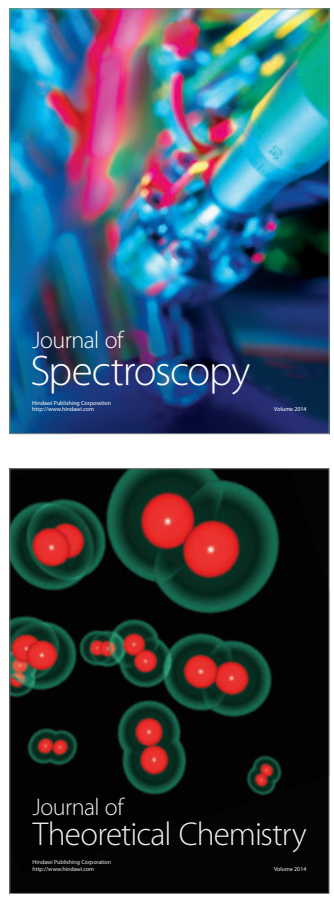
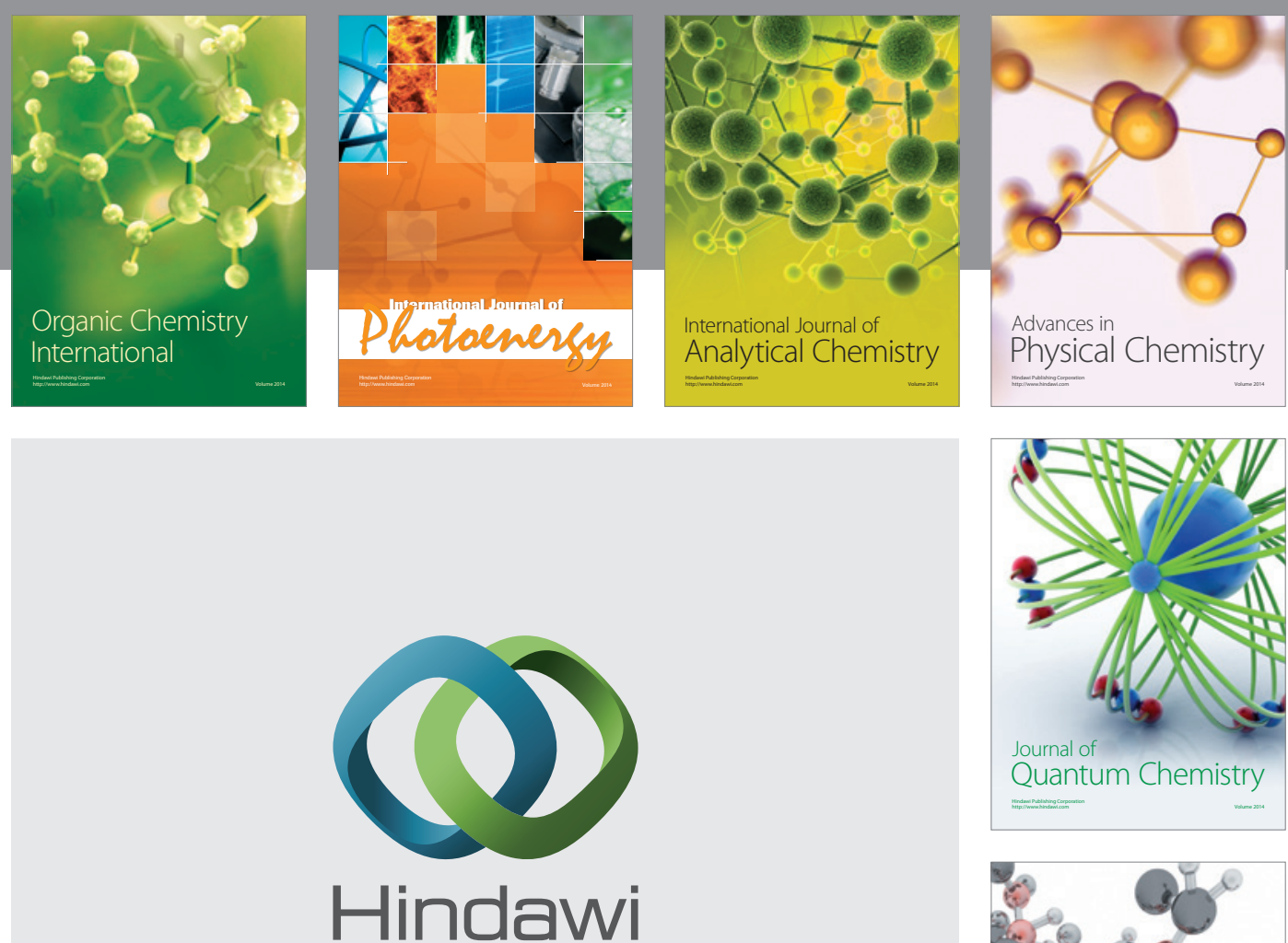

Submit your manuscripts at

http://www.hindawi.com

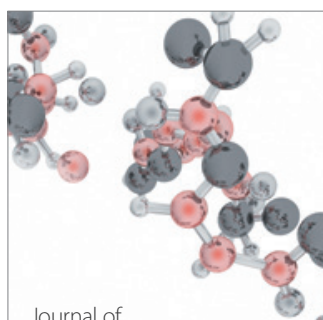

Analytical Methods

in Chemistry

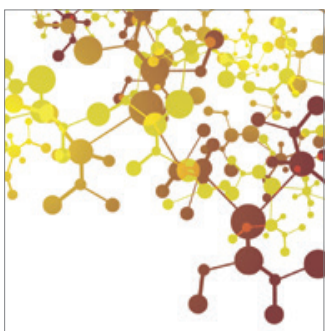

Journal of

Applied Chemistry

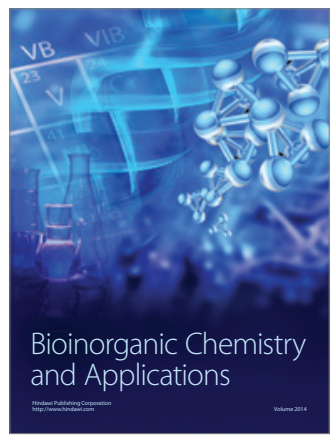

Inorganic Chemistry
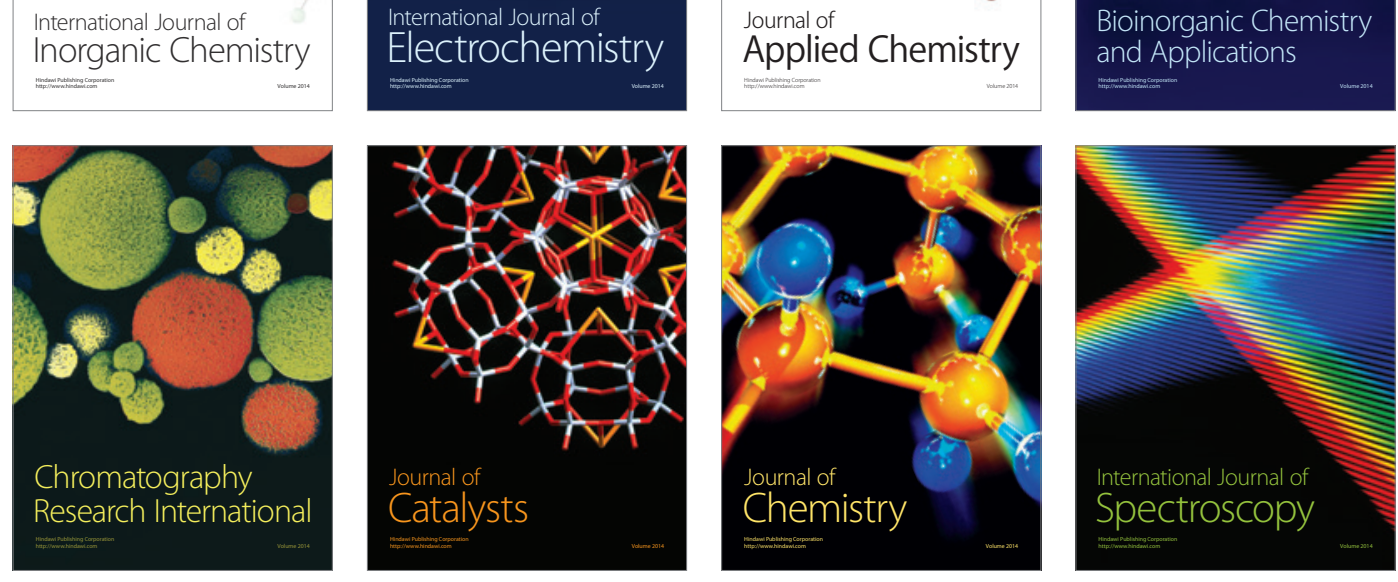